\title{
Ana Hatherly e um redimensionamento de postura lírica
}

Claudia Mentz Martins*

\section{Resumo}

Ana Hatherly é uma poeta portuguesa que estabelece uma (re)visão na poética lusa, enquanto artífice de um experimentalismo que ordena e reordena uma constante evolução de sua própria obra. Nossa proposta, neste texto, é a de olhar parte de sua poética presente em $O$ cisne intacto sob a ótica do homem contemporâneo, o qual assume o papel de leitor em processo de descobrimento de sua produção. As sucessivas reflexões, implícitas no fazer artístico da autora, são também objetivo de nosso próprio pensar e que encontra embasamento sobretudo em Octavio Paz, em $O$ Arco e a Lira, e Gillo Dorfles, em Elogio da Desarmonia.

Palavras-chave: Ana Hatherly. Poética. Modernidade. Criatividade. Originalidade.

\section{Introdução}

Ana Hatherly (Porto, 1929; Lisboa, 2015) pode ser considerada uma das artistas portuguesas mais significativas da contemporaneidade. Sua produção associa diferentes elementos que se complementam e que tornam sua produção

\footnotetext{
Graduada em Letras pela Faculdade Porto-Alegrense de Educação Ciências e Letras (FAPA), habilitação Português e Literaturas de Língua Portuguesa (1994/1) e habilitação em Inglês e Literaturas de Língua Inglesa e Norte-Americana (1994/2). Também pela FAPA, cursou Especialização em Literaturas: Brasileira e Infanto-Juvenil (1995). Fez mestrado em Linguística e Letras, área de concentração em Teoria da Literatura, pela Pontifícia Universidade Católica do Rio Grande do Sul (1998), e doutorado em Linguística e Letras, área de concentração em Teoria da Literatura, pela mesma instituição (2004). Realizou um pós-doutorado na Universidade Federal do Rio Grande do Sul (2009), em Literatura Brasileira, com bolsa Capes/Prodoc; e outro na Universidade de Lisboa (2014), em Lírica Portuguesa Contemporânea, também com bolsa Capes. Atualmente é professora associada na Universidade Federal do Rio Grande (Furg). Tem experiência na área de Letras, com ênfase em Teoria Literária, atuando nos seguintes temas: literatura brasileira (Modernismo \& Oswald de Andrade), literatura portuguesa contemporânea (poesia), imaginário (Durand \& Bachelard) e literatura e ensino (fundamental e médio). E-mail: claudiamartins@furg.br
}

Data de submissão: abril de 2020 - Data de aceite: julho de 2020 http://dx.doi.org/10.5335/rdes.v16i2.10384 
ímpar. Barroco, Experimentalismo e Concretismo são alguns dos caminhos seguidos para compreender a sua produção. No final dos anos 1950 e início dos anos 1960, é apontada como uma das primeiras poetas a trabalhar com a poesia concreta em Portugal. Porém, conforme entrevista concedida a Floriano Martins, em 2005, não se deixa limitar por essa experiência e não se permite a "uma leitura restritiva da própria aventura do ser em busca de si" (MARTINS, 2005, p. 14).

$\mathrm{Na}$ sua obra, percebemos uma inquietação poética que se faz presente num contínuo experimentalismo da linguagem, ocasionando uma perturbação na tradição da lírica portuguesa. Tal experimentalismo é visto, por Raquel Monteiro (2008, p. 20), como

[...] o estudo do potencial poético da escrita, a distribuição da linguagem, a exploração das possibilidades estruturais, a autonomização do signo, a substantivação da palavra e abandono de uma sintaxe convencional [...].

Os aspectos mencionados tornam a leitura dos poemas de Hatherly um desafio ao leitor. Não nos referimos a um desafio que busque desvendar o que está expresso em seus versos ou, se quisermos, apreender os sentimentos expostos. Trata-se de o leitor procurar olhar o mundo com os olhos de quem ainda não percebeu a sua necessidade de olhar, de ver o que está sendo dito e de como isso é feito. Está em pauta a percepção de um redimensionamento da postura lírica, isto é, de uma nova capacidade de perceber os conteúdos onde eles se ocultam, esquadrinhando novos sentidos e/ou novas razões para o que fazemos.

\section{A lírica de Hatherly em O cisne intacto}

A lírica de Hatherly possibilita que o sujeito se situe em uma perspectiva de amplitude. Ao leitor, ela convida à reação, seja a de uma parceria ou de rejeição à sua proposta poética. Não há determinações legíveis, quer na forma ou nas temáticas expressas nos seus poemas. A primeira impressão que temos é a de visualizar um trabalho artesanal de um escultor, enquanto elabora, na matéria palpável, o esboço projetado pela mente.

Nossa intenção é a de abordar alguns poemas que mobilizem nossos sentidos de modo especial. Buscamos uma possibilidade de diálogo com os versos da poeta, na medida em que os sentidos superem continuamente uma análise restritiva. Percebemos, na sua produção, uma adequação ao viver, ao vivenciar do homem atual, cujas emoções se dissolvem em necessidades materiais e se diluem em problemáticas extremamente amplas, indefinidas quanto aos seus desejos e/ou necessidades.

$\mathrm{Na}$ poesia de Hatherly, a palavra é matéria e forma, e muito se assemelha à escultura, trabalhada no espaço que 
possibilita a mobilidade da obra. Nada é definitivo ou fechado, nada é circunscrito ao tema, tudo é móvel, é dinâmico, num contínuo movimento experimental. Diríamos, a propósito de sua posição de artífice de uma nova poesia, que ela se utiliza de uma nova inventividade, de uma criatividade específica, que ultrapassa a explosão do sentimento lírico, fundamentando-se em cuidadosa elaboração, resultante de um presumível trabalho de construção e constituição da linguagem.

Utilizamos os termos "inventividade" e "criatividade" no sentido dado por Gillo Dorfles (1986) quando ele nos fala do desvio na estética contemporânea, aludindo aos espaços diferenciados, onde surgem os movimentos do novo, da ruptura sendo completada pela efetivação da "possibilidade criativa" e de um novo valor expressivo. Ressaltamos que o desvio não é uma interrupção ou um afastamento de uma trajetória que possa ser considerada confortável, mas deve ser considerado como uma possibilidade de renovação e/ou de recriação estética:

[...] mas [é] também [a partir da ideia de] renovação e reelaboração, enfim tornada possível pela brusca interrupção que terá tido lugar no percurso habitual de um acontecimento artístico. Ambos os fenómenos, por conseguinte - tanto o intervalo quanto o desvio - devem ser considerados como promotores de nova e diferente possibilidade inventiva (DORFLES, 1986, p. 90).
O experimentalismo de Ana Hatherly parece-nos um exemplo da possibilidade proposta por Dorfles, enquanto ela reage ao dogmatismo e aos valores segmentados e, acompanhando o movimento social do homem moderno, expande-se, ao mesmo tempo em que sintetiza. $\mathrm{O}$ uso de palavras em posições de sentido abertas se encontra com a síntese do sentido implícito.

No seu texto, "Notas para uma teoria do poema-ensaio", ao falar do experimentalismo poético, a poeta destaca a aproximação da poesia e da prosa e ressalta que o vanguardismo artístico se efetua em sucessivos desdobramentos. Ou seja, de época para época, as áreas vão se tornando mutáveis e permitindo novas combinações, as quais geram características peculiares:

A queda de fronteiras entre as artes exigida pelas vanguardas desde o princípio do século produziu-se de facto, inclusive o íntimo de cada uma delas, e hoje podemos assistir aos diferentes desdobramentos dentro de cada área específica que, por isso, em muitos casos, se tornou menos exclusiva (HATHERLY, 2001, p. 327).

Hatherly, certamente, contribui para essa dinamização de espaços, atuando na desconstrução discursiva da lírica tradicional, através da revisão da estética vigente, em busca de uma liberdade de criação. O termo criação tem, em nossa leitura, o sentido proposto por Octavio Paz (1982, p. 187), quando ele explicita que: 
A experiência poética é uma revelação de nossa condição original. E essa revelação é sempre resolvida numa criação: a de nós mesmos. A revelação não descobre algo exterior, que estava aí, alheio: o ato de descobrir entranha a criação do que vai ser descoberto: nosso próprio ser. Nesse sentido, pode-se dizer, sem temor de incorrer em contradição, que o poeta cria o ser.

A poeta se configura assim como instauradora dessa perspectiva de criação, enquanto redimensionadora da linguagem poética tradicional, ou ainda enquanto artífice de uma constituição do sujeito lírico da modernidade.

A ideia de modernidade, implícita no artesanato poético de Hatherly, implica no movimento humano que atualiza os valores, chegando até nós na ruptura de identidades pessoais e/ou sociais. Os conceitos de nossa modernidade imprimem imediatismos e utilitarismos ideológicos ao uso da linguagem, buscando uma forma consumível pelos mecanismos midiáticos, em acelerada expansão.

A poética provinda do processo criativo de Hatherly ultrapassa essa indefinição e faz com que seu texto gere uma reflexão e instale um processo de sucessivas efetivações do poema. Enquanto leitores, recebemos um olhar do sujeito lírico e assumimos o significado, não desse sujeito, mas do nosso, a partir de nossas vivências, sensações e imagens. Somos convidados a elaborar a nossa imagem com os elementos semânticos e formais presentes na criação de outrem.
Recorremos, novamente, a Octavio Paz (1982, p. 204-205, grifos do autor):

Depois da criação, o poeta fica sozinho: são outros, os leitores, que agora vão se criar a si mesmos ao recriarem o poema. Repete-se a experiência ao contrário: a imagem se abre diante do leitor e lhe mostra seu abismo translúcido. O leitor se debruça e despenca. $\mathrm{E}$ ao cair - ou ao ascender, ao penetrar nas salas da imagem e se abandonar ao fluir do poema - desprende-se de si para penetrar em 'outro de si mesmo' até então desconhecido ou ignorado.

Para desenvolver nossa proposta, deteremos a atenção em alguns poemas que compõem $O$ cisne intacto, obra que se encontra em Um calculador de improbabilidades, coletânea organizada pela própria poeta (HATHERLY, 2001, p. 262-265):

por sobre a onda correndo desliza o deslizador

na praia olhando pensamos

\section{deslizamos}

sabemos símbolos de mais

sobe o sabor do saber acima da indiferença

por onde passa

$$
\text { o saber }
$$


o sabor da diferença

o poeta é um guardador

guarda a diferença

guarda da indiferença

no incerto da voz

o tudo

ou

o todo

qual existe?

É possível?

necessário?

a firme

forma

afirma:

amor

a-mor-tendência

a-mor-cedência

a ti

ma ter ia

a etérea matéria

tem em comum com a forma

a norma

$$
\begin{aligned}
& \text { a alegria } \\
& \text { porém } \\
& \text { é isenta } \\
& \text { quando se une a elas } \\
& \quad \text { experimenta }
\end{aligned}
$$

quando escrevo sou ana

soberana
No poema inicial, à proposta da imagem segue-se a do eu lírico, assumidos, ambos, num plural que, no espaço imagético de uma ondulação, desliza para a simbologia, onde o conhecimento é suplantado pelo saber. Em nossa composição imagética, por meio da repetição do verbo "deslizar" e de seu substantivo “deslizador", somos levados pela sensação de indefinição do nosso próprio espaço, embora este nos seja visível. Parece-nos uma espécie de imagem da modernidade insegura - segundo propõe Bauman (2001) -, sem sugestões palpáveis para um futuro, o que se contrapõe aos tempos precedentes, em que as respostas para um futuro estavam claramente expostas na mente do homem dentro de seu contexto segmentado.

O segundo poema segue como um movimento contínuo ao primeiro, em que o saber se mostra contrário à indiferença, talvez fazendo o homem moderno buscar algo maior do que lhe é disponibilizado. Esse movimento não é de ruptura ou de radicalização, e sim de deslizamento, no sentido da continuidade no tempo. A própria estrutura gráfica desse poema - como o de quase todos os outros - induz ao movimento contínuo de avanços e de recuos, como numa alusão ao processo do aprendizado humano, que não obedece a uma linearidade e necessita, evolutivamente, de paradas e/ou retrocessos para sedimentar seus aprendizados, a fim de que sejam acrescentados novos conhecimentos. 
Ao início do terceiro poema, "o poeta é um guardador", encontramos o diálogo com Fernando Pessoa. Aqui o contraste se instala, talvez numa alusão às diferenças entre os heterônimos, enquanto símbolos das múltiplas possibilidades que podem se postar diante do homem moderno, ou seja, as diferentes oportunidades, para que ele possa instaurar-se como uma multiplicidade de sujeitos. $\mathrm{Na}$ nossa posição imagética, metaforizamos a ideia de que todas as respostas, isto é, as certezas do conhecimento, podem gerar apenas incertezas. $O$ poeta em si não se iguala aos demais indivíduos e nem com eles se preocupa de fato. Associamos os sentidos, por nós detectados, ao efêmero das relações humanas do homem moderno ou contemporâneo.

No quarto poema, "tudo" e "todo" perdem seu caráter de indefinição ao serem precedidos pelo artigo definido e ganham aspecto de totalidade. Todavia, pairam dúvidas sobre a possibilidade de assim serem ou ainda de precisarem dessa integridade. A forma indica, na continuidade do poema, o retorno ao "afirmativo", que se estabelece no "amor" de onde o sujeito lírico sai para a relação com o outro, fragmentando-se numa polissemia, a exemplo das relações dúbias e passageiras dos tempos vindouros à escritura. O contraste gera indagações e várias possibilidades de sentido explícitas na forma, que são facilmente apreensíveis ao sujeito leitor, cujo olhar estabelece a sua própria imagem.

O último poema, dessa sequência, "a etérea matéria", retoma o modo de a tradição poética manter sua vigência, através da norma, do conceitual emblemático, dos opostos que criam a forma, como em sentidos de amor/ódio, bem/ mal, alegria/tristeza, e assim por diante. A poética experimental trans-forma, transcendendo ao contrariar, ao criar novos olhares, permitindo a instauração do sujeito leitor, levando a linguagem para o sentido universal. A posse dos contrários já não tem mais a conotação de oposição, mas de questionamentos. Hatherly se permite ser um eu lírico nominado, criando com a "alegria", com outra norma, sem rompimentos e sem dilacerações. É a possibilidade da superação da "Ana" ao se fazer "soberana".

Em continuidade à análise de poemas que integram $O$ cisne intacto (HATHERLY, 2001, p. 277-280), reproduzimos um novo seguimento:

\author{
o domínio \\ o erotismo do domínio \\ do domínio irrisório \\ mas enorme
}

submeter ver tremer ver o tremor do outro

vencer o gelo 
o desdém veloz

a felicidade é um túnel

saber

é saber saber-te

sabermo-nos unir

unirmo-nos

é conhecermo-nos

sabermos ser

por fim sermos

é sabermos

sabermo-nos

conhecermos

a surda áspide

a culpa inédita

vai surgir

atribulada

antecipada

olha-te

olha-te e estremece

a relação

religiosa

empírica

aguarda-te

inverosímil

horrorosa

a culpa

é um ferro etéreo queima de todos os lados

fobias agressivas

ânsias indeterminadas

com o próprio ar inspiradas

desconcertantes

magistral

a invisível pressão do outro

de quem é a culpa

que te culpa

que aludido afã pretere

esta inversão

impassível

aluída

entre o horror

e o monstro

lineal

o eu

violento

violenta

volta à casa

amor

à casa sólita

desabrida

tua

mas se voltares

volta-te

revolta-te

o assédio

o ápice

o óbice

o súbito 
o sólito

o insípido

o que fere

o que foge

o que finge

revolta-te

revolta-te

revolta-te

Este segundo grupo de poemas se caracteriza por ser metapoético. Conforme a leitura transcorre, verificamos a visão que Hatherly tem da poesia e do fazer poético, a percepção dela sobre a arte, a qual expressa por meio do seu eu lírico, e a relação que esse estabelece com a palavra.

Em "o domínio", na primeira estrofe, nos três versos iniciais, há a presença do léxico "domínio", que se encontra diagramada quase na mesma posição. Isso intensifica seu sentido, mostrando a força de um sujeito em se impor sobre o outro por meio da poesia. A potência dessa força é ressaltada quando o domínio, mesmo sendo "irrisório", é "enorme". Notamos, nos versos, a presença mencionada de um "outro" que não fica imediatamente claro quem seja, havendo a possibilidade de ele ser o leitor.

O modo como a poesia - que podemos inferir como sendo a experimental - é vista fica explícito quando o sujeito lírico fala, cada vez mais incisivo e "veloz", que ela precisa "vencer/ o gelo/ o desdém". À poeta resta uma fuga, que é atravessar o túnel à espera da felicidade, isto é, da compreensão ou da aceitação de sua arte.

O poema que se segue também possui a repetição de um léxico, por três versos: "saber". Sua citação se dá em quatro momentos e, além do sentido já desenvolvido em poemas anteriores, podemos agregar o de uma conotação erótica, uma vez que o "saber [é] saber-te", fixando-se uma segunda pessoa, a qual se sabe unir. Tal interação é apontada num ciclo de ações em que os verbos "unir", "conhecer" e "saber" se apresentam numa evolução que leva ao domínio do prazer, entendido também como o saber do poema, aceitando-o e compreendendo-o. Além de, por meio da metáfora "surda áspide", indicar que a aprendizagem adquirida permite reconhecer uma intelectualidade reacionária ou tradicional, capaz de destilar seu veneno e prejudicar a poeta e sua poética.

Em "a culpa inédita", podemos inferir o tema da culpa que, inicialmente, numa visão católica, recrimina o prazer erótico; e, em segunda instância, relacionamos ao arrependimento que a poesia experimental pode exprimir em se opor à tradição, recusando-a de modo taxativo. O "olhar" se dá a alguém ou a algo, e a relação que se estabelece faz com que se aguarde algo fadado à impossibilidade.

A problemática da culpa é tão forte que tem continuidade no próximo poema. Nele, conferimos a definição para a culpa construída pelo eu lírico, 
a qual tem por base a religiosidade que permite o estabelecimento de um novo pecado original, pois a culpa em pauta é "inédita", havendo essa referência no poema anterior. No decorrer dos versos, $o$ leitor percebe a punição a ser incutida ao pecador - culpado tanto pelo viés erótico quanto pelo metapoético -, a sensação de desconforto e de opressão que lhe é imputada é imaginável ao ferro, é não dito, mas referido na pressão que o outro sofre durante o castigo.

Enquanto leitores, lembramos que a religiosidade é uma questão cultural muito significativa em Portugal - local de nascimento e de poetizar de Hatherly - e compreendemos o quanto esse assunto é significativo para a poeta, pois ela segue tratando dele no poema "de quem é a culpa”. Aqui, é apontado o existir de uma culpa pretérita que se transforma naquela do eu lírico e que acaba por gerar um afã que se põe entre o "horror" e o "monstro" que é "linear". A partir dessa leitura, notamos que, de modo mais específico que os demais, esse poema é em essência metapoético, porque "o eu/ violento/violenta" a linearidade, ou seja, o fazer poético convencional, regrado e normatizado.

Há, nesses poemas, uma explicitação quanto à violentação às formas previamente aceitas e à não observância a elas. Se, por um lado, a poeta revela um eu lírico pecador, agressivo e transgressor, por outro, assume feições sedutoras, pautadas na criatividade e na originalidade.

A proposta de voltar à casa, no penúltimo poema, lembra-nos de início as cantigas trovadorescas, pois o eu lírico deseja o retorno do ser amado à casa conhecida, que não contém conforto, mas é a de sua origem. Todavia, o "amor", ao fazer esse movimento, deve voltar e revoltar-se. Nesses versos, nós, leitores, percebemos que os sentimentos expressos não se restringem a aspectos amorosos; neles, há o embate no qual o artista se encontra entre o fazer poético tradicional e o experimental, sendo a volta à casa, à tradição; é a revolta, a experimentação.

Os motivos pelos quais o poeta deve se revoltar são listados no último poema. Nas três primeiras estrofes, conhecemos os elementos sobre os quais aquele deve se opor. Temos aspectos ligados ao erotismo, ao súbito que fere, ao solícito que foge, ao embaraço, ao estorvo, ao impedimento. $\mathrm{O}$ trabalho experimental é apontado como não sendo habitual ou semelhante ao já existente. $\mathrm{O}$ sujeito lírico é exortado ao longo dos versos, é o "tu" que necessita agir e que tem uma agressividade decrescente - "fere", "foge" e "finge" -, em função da necessidade inicial de impor sua arte, deve sempre revoltar-se contra a poética pré-estabelecida e pré-concebida, convencional e previsível. 
Nos poemas selecionados, fomos recriando-os. Neles, percebemos um impulso rítmico, sonoro, significativamente complementar à expressão gráfica e, igualmente, semântica. Um impulso que se funda numa relação dinâmica, aberta ao preenchimento de sentidos, ao refazimento de cada parte e do todo. A cuidadosa escolha lexical convida o leitor a elaborar um novo conhecimento. Os sentidos metafóricos alegóricos, alusivos, temporais, espaciais e sinestéticos são instrumentos recorrentes em Hatherly, remetendo a um renovar constante da criação, dinamizando as possibilidades de universalidade da sua poética.

Situamos essa poesia naquele movimento que Octavio Paz (1982) chama outridade, quando discute o fazer poético. De acordo com o autor (1982, p. 215, 217, grifos do autor):

[...] o homem avança sem cessar e cai, e a cada passo é outro e ele mesmo. A 'outridade' está no próprio homem.

[...]

O mesmo ocorre com as palavras: não estão nem dentro nem fora, mas são nós mesmos, fazem parte de nosso ser. São nosso próprio ser. E por fazerem parte de nós, são alheias, são dos outros: são uma das formas de nossa 'outridade' constitutiva. Quando o poeta sente-se desligado do mundo e de tudo, até a própria linguagem foge dele e se desfaz, ele próprio foge e se aniquila. E no segundo momento, quando decide fazer frente ao silêncio ou ao caos ruidoso e ensurdecedor, e balbucia e tenta inventar uma linguagem, é ele mesmo que se inventa e dá o salto mortal e renasce e é outro. Para ser ele mesmo deve ser outro. E a mesma coisa acontece com a linguagem: é sua porque é dos outros. Para torná-la realmente sua, recorre à imagem, ao adjetivo, ao ritmo, isto é, a tudo aquilo que a faz diferente. Assim, suas palavras são e não são suas. O poeta não escuta uma voz estranha; sua palavra e sua voz é que são estranhas: são as vozes do mundo, às quais ele dá um novo sentido. [...] A palavra poética é a revelação de nossa condição original porque por ela o homem, na realidade, se nomeia outro, e assim ele é ao mesmo tempo este e aquele, ele mesmo e o outro.

Ao assumir a linguagem poética de Hatherly como possibilidade de contato com a sua obra, estamos, enquanto leitores, assumindo igualmente essa outridade, o que nos torna cúmplices na arte de poetar.

Quando temos contato com os poemas de Ana Hatherly, somos levados à sensação de que eles não são apenas para serem lidos e nem que é possível apenas uma interpretação aos seus versos. Sua produção é para ser intensamente interiorizada, num processo que conduz a uma nova criação, tornando seus leitores novos vetores de sua arte. No início deste trabalho, propusemos a similaridade da arte de poetar com a de esculpir, e essa ideia ainda nos acompanha. Nada é claro, dizível ao senso comum. Poetar trata-se, sem dúvida, de uma arte de tessitura delicada, embora lide com matérias existenciais densas e problematizantes, como o ser homem na modernidade, como o instaurar-se interna e externamente.

Ao conduzir-nos para o olhar e depois para o refletir por meio de sua poética, 
Hatherly não rompe com o passado, mas o assume como parte efetiva do presente e, nos seus silêncios, abre as possibilidades para o futuro. Ao propor a aproximação entre prosa e poesia, em seu texto, Notas para uma teoria do poema-ensaio (HATHERLY, 2001), permite que a ideia de transformação supere a de negação. Ela nos fala também em um re-pensar a poesia, em uma re-formulação de sua poética, acompanhando a sua busca de mediação e de equilíbrio.

A sua poética segue a evolução da própria outridade, que necessita de retomadas e (re)visões em um processo ondulatório - de acordo com uma imagem recorrente em seus poemas - do tempo, numa modernidade indefinida, líquida em suas fronteiras e maleável na sua temporalidade. A multiplicidade do seu olhar e a materialidade de sua palavra propõem esse movimento permanente, gerando uma atualidade constante, a cada retomada de sua obra. Se fala do homem português, dos sentimentos portugueses, das ideologias, dos conceitos, das características, da composição do seu contexto, ela o faz com uma plasticidade aberta, constituída de modo a permitir que a re-criação dos sujeitos leitores ocorra em qualquer parte, independentemente do conhecimento dos elementos poetados. É o que podemos chamar de universalidade.

\section{Considerações finais}

Vemos a poética de Ana Hatherly ultrapassando as fronteiras simbólicas de história pessoal ou fonte de matéria-prima do artesanato poético. Relacionamos o exposto com as assertivas de T. S. Eliot (1991), quando se refere à função social da poesia, princípio que visualizamos assumido na arte da poeta. De acordo com Eliot (1991), a poesia é um elemento na personalidade social daquilo que definimos como cultura, sendo também com seus referenciais locais específicos uma forma de expressão dos questionamentos, locais e/ou nacionais, servindo como veículo de vivência da língua e elemento identificador de nacionalidades. Ao longo das afirmações desse autor, vemos que, para ele, a poesia estabelece a ligação com o futuro, num contínuo processo de atualização que não se prende à periodicidade datável.

A poética que nos propomos a olhar, certamente, fortalece a identidade cultural portuguesa, registra uma vivência inovadora da língua, afirma a possibilidade de diálogo com outras culturas, ultrapassando as fronteiras ideológicas e se contextualizando em outras vivências, no que já situamos como um processo de universalização. É a esse processo que intitulamos, ao início, de redimensionamento, uma espécie de superação de conceitos dogmatizados através de um re-pensar do trabalho com a linguagem. 
Ler a poesia de Ana Hatherly, quer em partes, quer no todo, é a oportunidade de o sujeito leitor poetar sem jamais ter se imaginado poeta.

No decorrer dos poemas selecionados, a poeta usa a linguagem conforme sua intenção artística, não apenas as palavras ganham significação, mas a sua disposição na página é parte do contexto, e sobre essas informações o leitor deve atentar. A criação de Ana Hatherly se faz a partir do que quer dizer e do que diz, do que fala e do que cala:

[...] há uma obliquidade fundamental entre o pensamento, o acto criador e o meio pelo qual ele se traduz. A obliquação fundamental situa-se entre o que se poderia dizer e $o$ que finalmente se diz: situa-se na parcialidade da concretização, ou seja, na escolha, na exclusão da potencialidade total (virtual) em favor da parcialização necessária (HATHERLY, 2002, p. 331).

Portanto, nos seus poemas, há a presença de grande sensibilidade, sem que, todavia, deixe de ser a razão a legitimadora. Sua estética se estabelece, desde seu princípio criador, com várias antinomias, sejam elas o fixo e o mutável, o perene e o efêmero, a presença e a ausência, etc. Os deslocamentos do sentido e do significado propiciam ao leitor a percepção pluriforme do mundo, bem como apontam para o fato de que as manifestações do real incorporam elementos que Dorfles (1986) denomina como "meta-artísticas", "para-artísticas", “anti-artísticas”. Para Dorfles (1986, p. 190), é provavelmente por meio desses elementos "que se poderá chegar a uma melhor possibilidade de entendimento recíproco entre os homens", e não só no campo artístico.

No redimensionamento da poética de Hatherly, percebemos a sua convergência para questões referentes ao processo de criação tratadas por Octavio $\mathrm{Paz}$ (1982), o qual salienta a necessidade de o poeta desenraizar a palavra de seus sentidos habituais e cotidianos, para lhe propiciar um renascimento. Porém, a apreensão da nova significação da palavra se dá através da interação do poeta com o leitor por meio do poema. É com essa interação "cíclica" entre os dois expoentes - poeta e leitor - que, na criação, leitura e recitação do poema, a poesia acontece.

\section{Ana Hatherly and a lyric posture resizing}

\section{Abstract}

Ana Hatherly is a Portuguese poet who establishes a (re)vision in Portuguese poetics as the orchestrator of an experimentalism that orders and reorders a constant evolution of her own work. Our proposal in this text is to look at part of her poetics in $\mathrm{O}$ cisne intacto from the perspective of the contemporary man, which takes the role of a reader in the process of discovering his production. The successive reflections, implicit in the author's artistic work, are also the object of our own thinking, which is 
grounded mainly on Octavio Paz, in $\mathrm{O}$ arco e a lira, and Gillo Dorfles, in Elogio da Desarmonia.

Keywords: Ana Hatherly. Poetics. Modernity. Creativity. Originality.

\section{Referências}

BAUMAN, Zygmunt. Modernidade líquida. Tradução de Plínio Dentzien. Rio de Janeiro: Jorge Zahar, 2001.

DORFLES, Gillo. Elogio da desarmonia. Tradução de Maria Ivone Cordeiro. Lisboa: Edições 70, [1986].

ELIOT, T. S. A função social da poesia. In: ELIOT, T. S. Poesias e poetas. Tradução de Ivan Junqueira. São Paulo: Brasiliense, 1991. p. 25-37.

HATHERLY, Ana. Um calculador de improbabilidades. Lisboa: Quimera, 2001.

MARTINS, Floriano. A visceralidade da escrita. In: MARTINS, Floriano. A idade da escrita e outros poemas. São Paulo: Escritura, 2005. p. 13-16.

MONTEIRO, Raquel. Sobre a recepção da PO.EX. In: TORRES, Rui (org.). Enquadramento teórico e contexto crítico da PO.EX. 2008. Disponível em: https:/po-ex.net/evaluation/ PDF/monteiro_recepcao.pdf. Acesso em: 01 dez. 2019.

PAZ, Octavio. O arco e a lira. Tradução de Olga Savary. 2. ed. São Paulo: Nova Fronteira, 1982. 